\title{
Editorial
}

\section{Special Issue on Diversity and Tensions in Social Work}

by

Vishanthie Sewpaul

Senior Professor, $\mathrm{PhD}$

University of KwaZulu-Natal

South Africa

and

Adjunct Professor

Department of Social Studies, University of Stavanger

Norway

E-mail: sewpaulv@ukzn.ac.za

Siv Oltedal

Professor, PhD

Department of Social Studies, University of Stavanger

Norway

E-mail: siv.oltedal@uis.no

Hildegunn Sagvaag

Professor, Dr.PH

Faculty of Health Sciences, University of Stavanger

Norway

E-mail: hildegunn.sagvaag@uis.no

DOI: https://doi.org/10.31265/jcsw.v15.i2.360

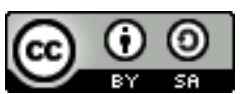

This work is licensed under a Creative Commons Attribution-ShareAlike 4.0 International License. 


\section{Special issue on diversity and tensions in social work}

We are pleased to produce this special issue on diversity and tensions in social work. In an intensely and rapidly globalizing world, people are progressively involved in socio-cultural, political and economic transnational practices, which have implications for social work education, research and practice and for social policy. As phenomena of internal and external displacements, and transnational migration spreads for a multitude of reasons, including wars and conflicts, hunger and starvation, poverty or a search for a better life, communities are increasingly characterized by heterogeneity. This calls for greater reflexivity for social workers to understand themselves and the people that they work with.

While respect for cultural diversities, and cultural sensitivity and responsiveness are central to social work, social workers need to maintain a fine balance and serve as cultural mediators when abuse, in various forms, occur in the name of culture. Paradoxically, while this call on the social work profession intensifies, as evident in the 2014 IASSW/IFSW Global Definition of Social Work and the 2018 IASSW (International Association of Schools of Social Work) Global Social Work Statement of Ethical Principles (GSWSEP), social work is being eroded and de-professionalized on account of the pervasive influences of neoliberalism and new public management (NPM). The concomitants to neoliberalism and NPM are emphases on technical and bureaucratic approaches, which detract from social work's focus on process, reflexivity, relationship building and the recognition of, and responsiveness to, the complex intersection of the personal and structural dimensions of people's lives.

The various contributors to this special issue deal with contextualizing social work and social work ethics within specific institutional, national and welfare system regimes as social workers engage with differences and diversities. They make valuable contributions by exploring different forms of tensions, gaps between theory and practice, between or within different institutional and empirical fields, and the tensions between the ideals of the profession and the realities of practice.

The first article, Two Tales of Community Work: Social Workers' Experiences of Role Changes in the Netherlands and Norway by Håvard Aaslund and Eelke Pruim, takes us on a journey across two diverse contexts wherein the roles of social workers have 
been challenged. Against the backdrop of neoliberalism, particularly in the Netherlands and of NPM, the authors discuss the role conflicts and ethical tensions experienced by social workers as they had to shift from traditional social work roles to adopting diverse roles as community workers. With the introduction of the Social Support Act in the Netherlands, that saw a greater transfer of responsibility onto people that social workers engage with, and a user-initiated project by homeless people in Norway, social workers described both pros and cons. However, the research revealed a greater emphasis on the negatives in relation to inadequate training for the new role demands, lack of clear boundaries in working at the community level, lack of communication of expectations of roles from employers, and having to adopt multiple roles that they had previously not been accustomed to.

The top down impositions initiated within the public sector, and the scaling down of resources in the Netherlands, contributed to some social workers being governed by fear, rather than a service orientation towards their work. Cohering with the discourses on neoliberalism and NPM, the authors conclude that, "Financial strains, individualization of responsibility and personal accountability became new challenges for the social workers, obscuring the roles and introducing new expectations." The solutions proposed include that education be directed at equipping graduates for these community-based roles, and they propose institutional level support, particularly in the form of professional guidance and appropriate supervision. Strikingly, is the absence of proposals for radical interventions to challenge neoliberal and NPM discourses and practices.

In Community Work as Opposition: Tensions and Potentials in a Formalistic Welfare Context, Christian Franklin Svensson and Vibeke Bak Nielsen take us to three community-based projects: The Thrift Shop, The Social Company and The New Grocery in Denmark. Against the backdrop of an highly institutionalized, formalized welfare system, where standardization of services is the norm, these projects highlight the uniqueness and diversities of people that social workers engage with, the premium of giving people voice, active participation, and the humanistic ideals of the social work profession. The projects serve as spaces of opposition to the standardization agendas of the municipality. The projects provide for a sense of community, networking, and neighbourhood development, embracing the values of 
social cohesion, solidarity, mutual commitment, trust and human relationships, without direct and open confrontation with the municipality.

The authors point to the discrepancy between the municipality's official narrative about working closely with people and it being an impersonal and distant institution. With increased centralization and bureaucratization of services there is a need to bring back services to the local levels, which the projects did. Despite the successes, there were pitfalls in securing authentic engagements of people, and lack of attention to the structural causes of human suffering, perhaps reflective of the projects' greater need to work alongside the public sector than adopting direct oppositional and advocacy strategies. Nonetheless, community social work is seen as an alternative to the impersonal and individualistic agendas of formalistic public sector welfare settings.

The third article in this issue, titled Social Workers' Perception of Practice with Lesbians, Gays and Bisexuals (LGBs) in Nigeria, is written by Elisabeth Onyedikachi George and Prince Chiagozie Ekoh. The authors describe the results of a qualitative study with a small sample of social workers to reflect how the law, culture and religion coalesce to produce deeply held homophobic attitudes and responses towards LGBs, and some outrageous myths about LGBs, which violate the values and ethical requisites of the social work profession. The GSWSEP (IASSW, 2018), Principle Three on Social Justice reads as:

Social workers promote social justice, in relation to society generally, and in relation to the people whom they work with. This means:

\subsection{Challenging discrimination \& institutional oppression}

a) Social workers challenge discrimination, which includes but is not limited to: physical and/or mental abilities, capacity, age, culture, gender identity, sexual orientation, race, ethnicity, language, religion, spiritual beliefs, political opinions, socio-economic status, poverty, class, family structure, relationship status and nationality (or lack thereof).

b) Social workers recognize how ideology, laws, policies, regulations, customs, or practices may create inequalities and prevent members of certain groups from equitable treatment.

Linked to the above is Principle Four on the Right to Self-Determination, with the following sub-principles: 
4.7 Social workers recognize that dominant socio-political and cultural discourses and practices contribute to many taken-for-granted assumptions and entrapments of thinking, which manifest in the normalization and naturalization of a range of prejudices, oppressions, marginalizations, exploitation, violence and exclusions.

4.8 Social workers recognize that developing strategies to heighten critical consciousness that challenge and change taken-for-granted assumptions for ourselves and the people whom we engage with, forms the basis of everyday ethical, anti-oppressive practice.

Thus, in including content on GLBs in social work curricula, as the authors propose, it is the forms of praxis that are critical in countering deeply held prejudices and discriminations. While religion, particularly Christianity and Islam, is used to argue that homosexuality is "not in our religion/culture", that it is a Western imposition, there is no acknowledgment that the introduction of these religions was a function of colonization and missionization. There is a wide breath of literature attesting that, through colonization and missionization, a Western or Eurocentric hegemony has come to characterize social work education, research and practice across the globe, including Africa. Anti-homosexuality, in many African countries, is constructed as an anti-colonial stance, yet paradoxically it is defended in the name of religions and cultures imported via colonization and missionization. Rather than a defensive blaming of Western values and cultures, greater headways might be made in promoting social justice and human rights by owning up to prejudices, discriminations and violations of human rights, and by truly living up to the core values of Afrocentricity.

At the heart of Afrocentricity is the transformative agenda, and the goal of liberating African peoples from the constraints of their own thinking, that the GSWSEP (2018) supports in relation to all people. Afrocentricity is, ideally, a non-hegemonic alternative to Eurocentrism. To construct Afrocentrism as superior to Eurocentrism is to fall into the same trap as the colonizers and neo-colonizers, and it is a negation of the more unifying goals of social work. Respect, responsibility towards others, integrity, reciprocity and emancipatory ideals are not distinguishing features of African societies only; these are shared universal values. We must reject dichotomous depictions of the West and the Rest, and support calls for unities in diversities through dialogue; tuning into the life worlds of people; responsiveness; 
reasoned debate; recognizing the power of care and compassion for self and the other; and of interdependence, reciprocity and validation of all people.

The article, on Negotiating Identities and Power: Adolescent Motherhood and Child Marriage in Central Malawi, by Elita Chamdimba and Janne Paulsen Breimo, introduces us to the complex dynamics of power in patriarchal contexts, and the pernicious consequences of normalizing gendered norms and dominant constructions of masculinity and femininity. Drawing on their qualitative research data with adolescent mothers, a key informant and community members, the authors describe how gender is played out in the day-to-day lives of adolescent mothers, particularly in relation to engaging in domestic chores, impacts on education, lack of partner support and manifestations in domestic violence. The results of the research, however, present a story of hope and agency as the young mothers gained re-entry into school, with the authors seeing education being "a bridge between how they (adolescent mothers) are currently 'doing gender', 'who I am', and the way they desire to do gender, 'who I want to be'", and as they terminated their child marriages. Of particular salience in the Malawian context is the powerful roles of traditional leaders, who are "custodians of culture" in "collaborating with adolescent mothers to end child marriage", in the words of the authors. This recognition, in addition to the inclusion of boys and men to open up "the possibility of creating expressions of power (and/or empowerment) that benefit all people, because 'doing gender' is not done in isolation of either sex" (author words) hold important lessons for other contexts where child marriages are practiced.

The authors point to Indigenous approaches that meet the contextual realities of Malawi, which is an important lesson in dealing with the complex tensions between culture and human rights. The latest GSWSEP (IASSW, 2018) attempts a balance between culture and human rights by calling on social workers to not stretch the boundaries of moral relativism to the point where the rights of some groups of persons are violated (Principle 3.2b), and for social workers to adopt the role of cultural mediators (Principle 2.3). Managing the tensions between the universal and the particular does not depend on formulaic answers. In recognition of the fact that no code can make social workers ethical, the IASSW (2018) calls for social workers to uphold ethical practices through "processes of constant debate, self-reflection, 
willingness to deal with ambiguities, and to engage in ethically acceptable processes of decision-making" (p. 1). In some instances, it is, as the authors describe, more prudent for social workers to call upon traditional leaders, who hold more power and authority, to serve as cultural mediators in the interests of social justice, and in protecting and promoting human rights.

The final article in this issue titled, Navigating the Multifaceted Landscape of Culture and Social Work: A Qualitative Evidence Synthesis of Cultural Competence and Cultural Sensitivity in Practice, is written by Maria Gussgard Volckmar-Eeg and Elisabeth Enoksen. In this article the authors provide a synthesis of previous empirical research on social workers' understandings and experiences when operationalizing the core concepts related to culture into practice. Through an analysis of 12 empirical studies, the authors discuss the following four challenges that social workers experienced in their efforts to operationalize cultural concepts: 1 ) Who to define as culturally diverse service-users, 2) what aspects of culture to consider in encounters with culturally diverse service-users, 3) how to consider and approach these aspects of culture, and 4) the capacity to work in a culturally appropriate manner within the organizational context where the work was undertaken.

Within their small sample, the authors found huge variations in the focus and definitions of "culturally diverse service-users," which have implications for social workers' understanding and operationalization of cultural competence and cultural sensitivity in practice settings. The authors conclude that cultural competence and cultural sensitivity is a complex field, in relation to challenges in ascertaining who constitutes culturally diverse groups, the need to recognize individual uniqueness and differences within defined groups, the lack of clarity of what is expected from social workers in working with cultural diversities, and the influence of contextual, organizational factors in hindering or promoting cultural sensitivity and responsiveness. With regard to the latter, they highlight, as impeding factors, NPM features of high caseloads, work pressures, close scrutiny and control of social workers, and lack of time to engage in deep reflexivity and the kinds of active and empathetic listening and responsiveness required to engage with people in meaningful ways. Social workers' willingness to deal with uncertainty and ambiguity, 
and their willingness to be for the other, are strengths in dealing with individuals within diverse groups. Rather than a proliferation of additional concepts, which obscures diversity practices, the authors call for greater reflexivity in social work.

International Association of Schools of Social Work (2018) Global Social Work Statement of Ethical Principles. Available at: https://www.iassw-

aiets.org/2018/04/18/global-social-work-statement-of-ethical-principles-iassw/. 